\title{
EFFECTS OF HYDROXYETHYL STARCHES ON BLOOD SUGAR LEVELS UNDER SUBARACHNOID BLOCK DURING SURGERY
}

\author{
Abdul Hakim ${ }^{1}$, Naseer Ahmad Dar², Mushtaq Ahmad Rather ${ }^{3}$ \\ ${ }_{1}^{1}$ Assistant Professor, Department of Anesthesiology and Critical Care, GMC, Srinagar. \\ ${ }^{2}$ Senior Resident, Department of Anesthesiology and Critical Care, GMC, Srinagar. \\ ${ }^{3}$ Senior Resident, Department of Anesthesiology and Critical Care, GMC, Srinagar.
}

\begin{abstract}
Fluid resuscitation is an important part of the management for hypovolemic shock in an Intensive Care Unit (ICU) or inside an Operating Room (OR), and colloids are used widely to serve this purpose. We studied and compared the effects of intravenous fluid (Hydroxyethyl starch and ringer lactate) on blood sugar level in patients undergoing surgery under subarachnoid block. 60, ASA grade 1, non-diabetic patients, 20 to 60 years of age, weighing 40 to $70 \mathrm{~kg}$, undergoing elective lower limb or lower abdominal surgical procedures, which were anticipated to complete within two hours were selected and randomly divided into three groups and preloaded with either Ringer's Lactate (Group 1) 20ml/kg, 6\% Hydroxyethyl starch-450 (Group 2) 10ml/kg and 6\% Pentastarch 200 as preloading solution (Group 3) respectively over a period of 30 minutes prior to spinal anaesthesia. Blood glucose levels were significantly increased in Group 2 and Group 3 (p value $<0.05$ ) from the baseline and slightly higher in Group 3 than Group 2.
\end{abstract}

\section{KEYWORDS}

Ringer Lactate, 6\% Hydroxyethyl Starch-450, 6\% Pentastarch 200, Spinal Anaesthesia, Blood Glucose Levels.

HOW TO CITE THIS ARTICLE: Abdul Hakim, Naseer Ahmad Dar, Mushtaq Ahmad Rather. "Effects of Hydroxyethyl Starches on Blood Sugar Levels Under Subarachnoid Block During Surgery." Journal of Evolution of Medical and Dental Sciences 2015; Vol. 4, Issue 100, December 14; Page: 16529-16532, DOI: 10.14260/jemds/2015/2460

\section{INTRODUCTION}

Colloids are used as preloading fluids prophylactically to limit complications following sympathetic blockade in central neuraxis blockade.1,2,3 Colloid-crystalloid combinations are regularly being used as priming fluids in cardiopulmonary bypass circuits as well.4,5 The introduction of artificial colloids has heralded a new alternative for volume expansion.

Hydroxyethyl starch solutions are now frequently used for volume expansion in critically ill patients. ${ }^{6}$ and for preloading prior to the administration of spinal anaesthesia.7,8 Commercially available Hydroxyethyl starch solutions contain large ethylated starch or glucose polymers that are metabolized by serum amylases to produce smaller molecules of starch polymers and free glucose.

Thus the potential exists for hydroxyethyl solutions to induce or potentiate hyperglycemia, particularly when given to patients who have a diminished ability to metabolize exogenous glucose viz. patients with diabetes mellitus.

The stress response can lead to adverse responses like hyperglycemia, hypertension, tachycardia and increased catabolism. Among the above mentioned responses, hyperglycemia can be detrimental to the well-being of the patient.9,10 Hyperglycemia can potentiate brain, spinal cord and renal damage by ischemia.

It blights the white blood cell functions and impairs wound healing. Moreover it decreases gastric emptying time.

Financial or Other, Competing Interest: None.

Submission 07-11-2015, Peer Review 08-11-2015,

Acceptance 09-12-2015, Published 12-12-2015.

Corresponding Author:

Mushtaq Ahmad Rather,

Senior Resident,

Department of Anesthesiology and Critical Care,

GMC, Srinagar-190006.

E-mail: mushtaqahmad767@gmail.com

DOI:10.14260/jemds/2015/2460
Central neural blockade commenced before the surgical incision significantly reduces or abolishes the stress response to surgery, particularly in pelvic and lower limb surgeries. ${ }^{11}$ Hence, we chose to carry out the study in patients undergoing surgery under regional anaesthesia to diminish any confounding factor.

Hydroxyethyl starches, which are made up of large ethylated starch or glucose polymers are metabolised by serum amylases to produce smaller molecules of starch polymers and free glucose residues. Even these carry a potential to accelerate blood glucose levels, subsequent to intravenous administration, under stressful conditions. ${ }^{12,13,14,15}$

Stress response to surgery and the catecholamine release following it is itself known to induce some amount of hyperglycemia, but this remains confined to a limited extent. 16,17 An additive hyperglycemic response secondary to the metabolism of infused intravenous fluids can thus prove detrimental to the well-being of the patient if ignored.

Considering these potential ill-effects of hyperglycemia in the peri-operative period on the well-being of patients and on the outcome of surgery, we carried out the following study with an objective to examine and compare the effects of $6 \%$ Hydroxyethyl starch-450 on blood sugar levels, during surgery under spinal anaesthesia and their potential to induce or potentiate hyperglycemia.

Taking into consideration the ill effects of hyperglycemia in the perioperative period and the frequent use of hydroxyethyl starches as volume expanders, the present study aimed to examine the effects of $6 \%$ Hetastarch450 and $6 \%$ Pentastarch-200 on the blood glucose levels in nondiabetic patients undergoing surgical procedures under spinal anaesthesia. 


\section{MATERIAL AND METHODS}

This present study was carried out in the Postgraduate Department of Anaesthesiology and Critical Care and was done in Government Hospital for Bone and Joint Surgeries and Government Lalla Ded Hospital (Associated hospitals of Government Medical College, Srinagar).

Following an approval from the Institutional Ethics Committee, patients included in this study was informed about the procedure and a written informed consent was taken from all of them; 60 , ASA grade 1 , non-diabetic patients, 20 to 60 years of age, weighing 40 to $70 \mathrm{~kg}$, undergoing elective lower limb or lower abdominal surgical procedures, which were anticipated to complete within two hours were selected and randomly divided into three Groups. These patients were preloaded with either Ringer's Lactate (Group 1) $20 \mathrm{ml} / \mathrm{kg}$, $6 \%$ Hydroxyethyl starch-450 (Group 2) $10 \mathrm{ml} / \mathrm{kg}$ and $6 \%$ Pentastarch 200 as preloading solution (Group 3) respectively over a period of 30 minutes prior to spinal anaesthesia through an 18-guage intravenous cannula. The patients were equally distribution $(n=20)$.

Patients on regular use of steroids and ascorbic acid were excluded from the study, as also patients with a low haematocrit $(\mathrm{PCV}<30 \%)$. All the procedures which were prolonged due to anaesthetic or surgical complications or those requiring blood transfusion due to more than predicted intra-operative blood loss were excluded as well.

The procedures followed were in accordance with the ethical standards on human experimentation in our institution. The patients were informed about the study and a written informed consent was taken for the same.

Patients with diabetes mellitus, on drugs that cause hyperglycemia such as acetaminophen, ascorbic acid, steroids; on drugs that cause hypoglycemia such as octreotide and patients with a low hematocrit value $(\mathrm{PCV}<30 \%)$ were excluded from the study.

All necessary investigations were noted and the patients were informed about the study and a written informed consent was taken for the same. All patients were premedicated with inj. glycopyrrolate $0.2 \mathrm{mg}$ intramuscularly half an hour prior to induction of anaesthesia. No sedation was given as premedication. The basal pulse rate and blood pressure of the patients were recorded.

The patients were allocated randomly to one of the three Groups. Group I (RL) patients received Ringer's Lactate $20 \mathrm{mlkg}-1$ over a period of half an hour as preloading prior to spinal anaesthesia, Group II (HS) patients received 6\% Hetastarch-450 $10 \mathrm{mlkg}-1$ over a period of half an hour as preloading prior to spinal anaesthesia and Group III (PS) patients received $6 \%$ Pentastarch-200 10mlkg-1 over a period of half an hour as preloading prior to spinal anaesthesia.

An intravenous access was achieved with an 18- gauge intravenous cannula. As soon as the vein was cannulated, a sample of blood was drawn for testing the blood sugar level using the one touch II glucometer (Johnson and Johnson).

The reading obtained was considered as the basal (Zero) reading. As per the allocated Group the intravenous fluid was started and preloading was accomplished with the calculated dose following which spinal anaesthesia was administered and the level was noted.

After preloading with the assigned intravenous fluid, the patients received normal saline as subsequent intravenous fluid till the final blood sugar reading was taken at the end of six hours from the basal reading. Subsequent blood sugar readings were taken at fifteen minute intervals from the basal reading for the first hour, followed by one hourly reading for six hours from the basal reading. After all the ten blood sugar values were recorded, the differences in blood sugar values were calculated.

\section{STATISTICAL ANALYSIS}

For statistical analysis of the clinical data obtained, the Analysis of Variances (ANOVA) with Bonferroni's post-hoc test was applied, $\mathrm{P}<0.05$ was considered to be significant and $\mathrm{P}<0.001$ was considered to be highly significant.

\section{RESULTS}

In our study, there was no statistically significant difference regarding the demographic profile of patients.

\begin{tabular}{|c|c|c|c|c|}
\hline Parameter & Group I $(M \pm S D)$ & Group II (M \pm SD) & Group III (M \pm SD) & P value \\
\hline Age & $40.2 \pm 8.087$ & $41.5 \pm 10.400$ & $39.5 \pm 8.775$ & 0.790 \\
\hline Male : Female & $11: 9$ & $12: 8$ & $9: 11$ & 0.626 \\
\hline Weight(kg) & $56.4 \pm 6.029$ & $56.6 \pm 7.104$ & $54.4 \pm 7.271$ & 0.524 \\
\hline
\end{tabular}

The baseline mean blood glucose levels at onset of preloading in all the three Groups were $73.05 \pm 2.259 \mathrm{mg} / \mathrm{dl}$ (Group I), $75.5 \pm 2.743 \mathrm{mg} / \mathrm{dl}$ (Group II) and $76 \pm 2.271 \mathrm{mg} / \mathrm{dl}$ (Group III), which were comparable. Comparison of the average rise in the blood sugar levels and average difference in the blood sugar levels in the three Groups is shown in Table 2 and 3.

\begin{tabular}{|c|c|c|c|}
\hline $\begin{array}{c}\text { Time } \\
\text { (Mins) }\end{array}$ & $\begin{array}{c}\text { Average Rise in Blood Sugar } \\
\text { level in Group I (in mg\%) }\end{array}$ & $\begin{array}{c}\text { Average Rise in Blood Sugar Level } \\
\text { in Group II (in mg\%) }\end{array}$ & $\begin{array}{c}\text { Average Rise in Blood Sugar Level } \\
\text { in Group III (in mg\%) }\end{array}$ \\
\hline Pre-op BSL & $73.05 \pm 2.259$ & $75.5 \pm 2.743$ & $76 \pm 2.271$ \\
\hline 0 & $72.15 \pm 2.852 \#(0.54)$ & $69.8 \pm 4.595^{*}(0.04)$ & $71.05 \pm 1.959^{*}(0.03)$ \\
\hline 15 & $73.25 \pm 2.268 \#(0.87)$ & $92.4 \pm 4.37^{*}(0.03)$ & $93.1 \pm 3.851^{*}(0.02)$ \\
\hline 30 & $74.05 \pm 2.645 \#(0.65)$ & $100.6 \pm 3.775^{*}(0.02)$ & $101.5 \pm 3.426^{*}(0.04)$ \\
\hline 45 & $74.5 \pm 2.763 \#(0.54)$ & $103.55 \pm 2.929^{*}(0.04)$ & $104.2 \pm 5.435^{*}(0.02)$ \\
\hline 60 & $75.25 \pm 3.307 \#(0.65)$ & $106.3 \pm 3.799^{*}(0.03)$ & $107.05 \pm 2.837^{*}(0.02)$ \\
\hline 120 & $76.1 \pm 2.024 \#(0.55)$ & $108.65 \pm 3.514^{*}(0.02)$ & $109.45 \pm 2.685^{*}(0.04)$ \\
\hline 180 & $74 \pm 2.317 \#(0.91)$ & $106.6 \pm 4.661^{*}(0.03)$ & $103.55 \pm 3.634^{*}(0.01)$ \\
\hline 240 & $73.75 \pm 2.845 \#(0.86)$ & $102.4 \pm 2.303^{*}(0.04)$ & $102.4 \pm 3.033^{*}(0.02)$ \\
\hline 300 & $73 \pm 2.449 \#(0.67)$ & $100.6 \pm 2.78^{*}(0.04)$ & $99.95 \pm 2.328^{*}(0.04)$ \\
\hline 360 & $71.95 \pm 2.946 \#(0.74)$ & $100.3 \pm 2.774^{*}(0.04)$ & \\
\hline \multicolumn{4}{|r|}{ Table 2: Comparison of the Average Rise in the Blood Sugar Levels } \\
\hline
\end{tabular}




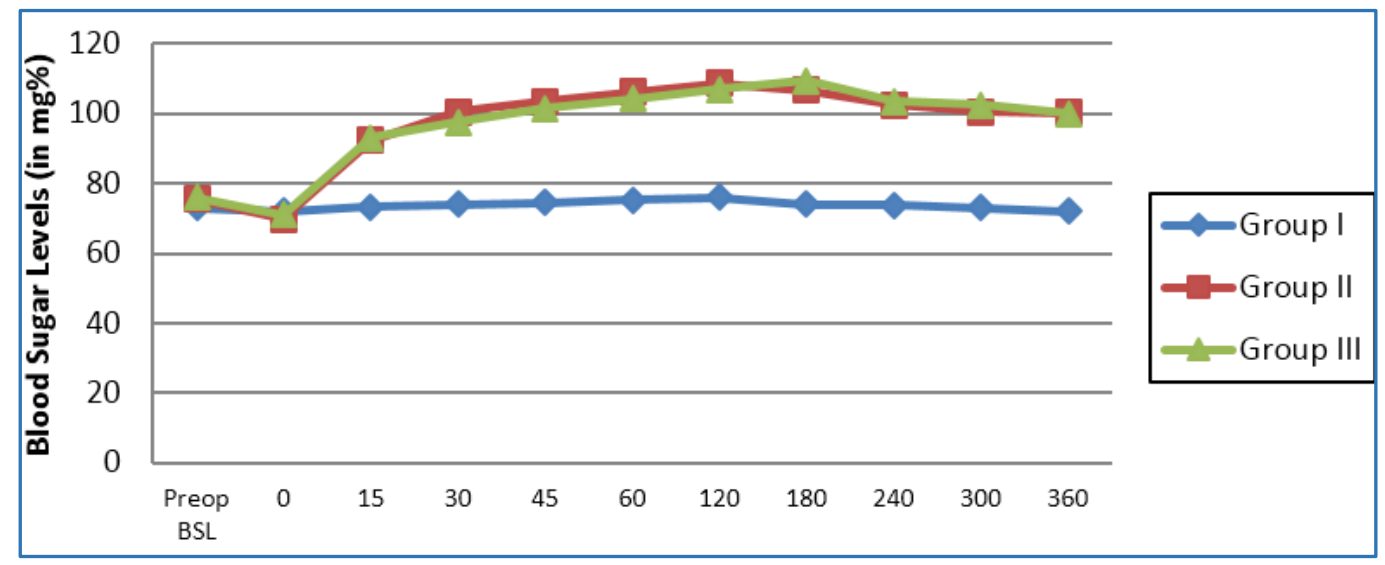

Fig. 1: Average Rise in the Blood Sugar Levels with Ringer's Lactate, Hetastarch and Pentastarch

\begin{tabular}{|c|c|c|c|}
\hline $\begin{array}{c}\text { Time } \\
\text { (Mins) }\end{array}$ & $\begin{array}{c}\text { Average difference in Blood Sugar } \\
\text { Level in Group I (in mg\%) }\end{array}$ & $\begin{array}{c}\text { Average difference in Blood Sugar } \\
\text { Level in Group II (in mg\%) }\end{array}$ & $\begin{array}{c}\text { Average difference in Blood Sugar } \\
\text { Level in Group III (in mg\%) }\end{array}$ \\
\hline 15 & $2.5 \pm 2.188$ & $17.05 \pm 4.774^{*}(0.03)$ & $17.05 \pm 5.021^{*}(0.02)$ \\
\hline 30 & $3.45 \pm 2.585 \#(0.09)$ & $25.1 \pm 5.32^{*}(0.02)$ & $21.5 \pm 4.059^{*}(0.03)$ \\
\hline 45 & $3.5 \pm 2.351 \#(0.07)$ & $28.1 \pm 3.523^{*}(0.03)$ & $28.65 \pm 4.344^{*}(0.04)$ \\
\hline 60 & $3.75 \pm 2.882 \#(0.06)$ & $30.8 \pm 5.022^{*}(0.04)$ & $31.05 \pm 3.432^{*}(0.03)$ \\
\hline 120 & $3.6 \pm 2.303 \#(0.08)$ & $33.1 \pm 4.962^{*}(0.03)$ & $31.15 \pm 3.486^{*}(0.04)$ \\
\hline 180 & $2.85 \pm 1.725 \#(0.10)$ & $31.25 \pm 4.587^{*}(0.02)$ & $27.6 \pm 4.604^{*}(0.03)$ \\
\hline 240 & $3.2 \pm 2.093 \#(0.93)$ & $27.2 \pm 4.06^{*}(0.01)$ & $24.45 \pm 3.591^{*}(0.04)$ \\
\hline 300 & $2.8 \pm 2.016 \#(0.87)$ & $25.1 \pm 4.656^{*}(0.04)$ & $2.656^{*}(0.04)$ \\
\hline 360 & $2.65 \pm 2.641 \#(0.98)$ & $24.75 \pm 4.266^{*}(0.03)$ & \\
\hline & Table 3: Comparison of the Average difference in the Blood Sugar Levels in the Three Groups \\
\hline
\end{tabular}

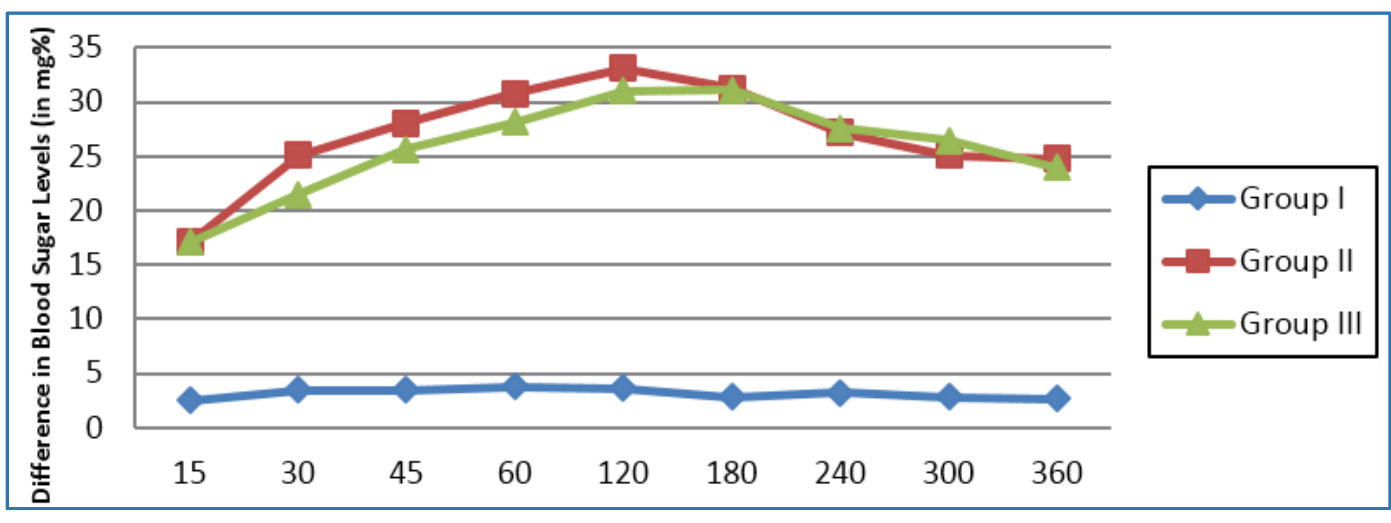

Fig. 2: Average difference in the Blood Sugar Levels at Various Time Intervals (In min)

In Group I, patient's blood sugar level at various interval of time is statistically insignificant ( $p>0.05$ ), while in Group II and Group III blood sugar level were significant ( $p<0.05)$.

\section{DISCUSSION}

This study is intended to examine the possibility of starches and Dextrans producing hyperglycemia, in spite of their pharmacodynamic potential to cause the same.

The maximal blood glucose levels in Group I increased from an average basal value of $73.05 \pm 2.259 \mathrm{mg} \%$ to $76.1 \pm 2.024 \mathrm{mg} \%$ at the end of two hours, an increase of only $3.6 \pm 2.303 \mathrm{mg} \%$, which was not statistically significant ( $p>0.05$ ). After this peak at two hours, the blood sugar levels gradually declined over the next four hours to $71.95 \pm 2.946 \mathrm{mg} \%$ with an average difference of only
$2.65 \pm 2.641 \mathrm{mg} \%$ from the basal reading, which was not statistically significant ( $p>0.05)$ as shown in Table 2 and 3 .

The maximal blood glucose level in Group II was observed at the end of two hours, which was similar to Group I. The blood glucose levels increased from a basal value of $75.5 \pm 2.743 \mathrm{mg} \%$ to $108.65 \pm 3.514 \mathrm{mg} \%$ an increase of $33.1 \pm 4.962 \mathrm{mg} \%$, which was statistically significant $(\mathrm{P}<0.05)$. After this maximal increase, the levels gradually declined over the next four hours to $100.3 \pm 2.774 \mathrm{mg} \%$ with an average difference between of $24.75 \pm 4.266 \mathrm{mg} \%$ from the basal reading, which was statistically significant $(\mathrm{p}<0.05)$ as shown in Table 2 and 3.

The maximal blood glucose levels in Group III increased from an average basal value of $76 \pm 2.271 \mathrm{mg} \%$ to $109.45 \pm 2.685 \mathrm{mg} \%$ at the end of three hours, an increase of $31.15 \pm 3.486 \mathrm{mg} \%$ which was statistically significant $(\mathrm{p}$ 
$<0.05)$. After this maximal increase the levels gradually declined over the next three hours to $99.95 \pm 2.328 \mathrm{mg} \%$, an average difference of $24.0 \pm 2.656 \mathrm{mg} \%$ from the basal value, which was statistically significant $(\mathrm{p}<0.05)$.

In Group I patients the blood sugar level at the end of fifteen minutes was $73.25 \pm 2.268 \mathrm{mg} \%$ an average difference of only $2.5 \pm 2.188 \mathrm{mg} \%$ from the basal value, which was not statistically significant $(p>0.05)$. The blood sugar levels increased marginally over the next six hours as shown in Table 2 and 3.

In Group II the blood sugar level at the end of fifteen minutes was $92.4 \pm 4.37 \mathrm{mg} \%$, an increase of $17.05 \pm 4.774 \mathrm{mg} \%$ from the basal values, which was statistically significant ( $p$ $<0.05$ ). This increase in blood sugar level in Group II occurred prior to any surgical stimulus and was sustained over the next six hours. There was a statistically significant increase in the blood sugar levels in Group II in comparison to Group I at the various time intervals at which the blood sugar readings were taken. The final average blood sugar level of $100.3 \pm 2.774 \mathrm{mg} \%$ as well as the final average difference of $24.75 \pm 4.266 \mathrm{mg} \%$ in Group II was still higher than the final average blood sugar value of $71.95 \pm 2.946 \mathrm{mg} \%$ and the final average difference of $2.65 \pm 2.641 \mathrm{mg} \%$ in Group I as shown in Table 5 and 6.

In Group III, the average blood sugar level at the end of fifteen minutes was $93.1 \pm 3.851 \mathrm{mg} \%$, an increase of $17.05 \pm 5.021 \mathrm{mg} \%$ from the basal values which was statistically significant $(\mathrm{p}<0.05)$. This increase occurred prior to any surgical stimulus and was sustained over the next six hours. There was a statistically significant increase in the blood sugar levels in Group III in comparison to Group I at the various time intervals at which the blood sugar readings were taken. The final average blood sugar level of $99.95 \pm 2.328 \mathrm{mg} \%$ as well as the final average difference of $24.0 \pm 2.656 \mathrm{mg} \%$ in Group III was still higher than the final average blood sugar value of $71.95 \pm 2.946 \mathrm{mg} \%$ and final average difference of $2.65 \pm 2.641 \mathrm{mg} \%$ in Group I as shown in Table 2 and 3.

Our findings were consistent with the study conducted by Dr. Shailesh S. Murthy, et al. (2004).13 In their study, they observed a significant rise in the blood sugar levels with the infusion of Hydroxyethyl starches in comparison with Ringer's lactate solution. The statistically significant $(\mathrm{P}<0.05)$ rise in blood sugar levels was evident within fifteen minutes of starting the infusion prior to the surgical stimulus. The peak rise in blood sugar levels was recorded at two hours for $6 \%$ Hetastarch-450 and at three hours for 6\% Pentastarch200 , which was again statistically significant $(\mathrm{P}<0.05)$, albeit within physiological limits.

\section{CONCLUSION}

Since spinal anaesthesia was used as a standard technique of choice in all the patients, the stress response to anaesthesia and surgery was minimal in comparison to general anaesthesia in the three study Groups. The immediate rise in blood sugar levels within fifteen minutes of starting the infusion without any surgical stimulus and no concomitant rise in the Ringer's lactate Group as shown in our study (Table 2 and 3) as compared to use of Hydroxyethyl starches. The increase in blood sugar concentrations was within physiological limits after the use of Hydroxyethyl starches namely 6\% Hetastarch-450 and 6\% Pentastarch-200.

\section{REFERENCES}

1. Dubois MJ, Vincent IL. Colloid fluids. In: Hahn RG, Prough DS, Svensen $\mathrm{CH}$, editors. Perioperative Fluid Therapy. $1^{\text {st }}$ ed. New York: Wiley; 2007. p. 153-611.

2. Buggy D, Higgins P, Moran C, et al. Prevention of spinal anaesthesia induced hypotension in the elderly: Comparison between preanaesthetic administration of crystalloid, colloid and no prehydration. Anesth Analg 1997;84:106-10.

3. Aitkenhead AR, Rowbotham DJ, Smith G. Text book of Anaesthesia. 3rd edn. New York Churchill Livingstone, imprint of Harcourt Publishers; 2001. p. 301.

4. Nussmeier NA, Searles BE. The next generation of colloids: Ready for "prime time?" Anesth Analg 2009;109:1715-7.

5. Lilley A. The selection of priming fluids for cardiopulmonary bypass in the UK and Ireland. Perfusion 2002;17:315-9.

6. Hankeln K, Beez M. Haemodynamic and oxygen transport correlates of various volume substitutes in critically ill inpatients with various aetiologies of haemodynamic instability. International Journal of Intensive Care 1998;9-11.

7. Baraka AS, Ghabach T. Intravenous administration of polymerized gelatin versus isotonic saline for prevention of spinal induced hypotension. Anaesth Analg 1974;78:301-05.

8. Koski E, Tuppurainen, Mattila M, et al. Hydroxyethyl starches, Dextran and Balanced salt Solution in Correction of Hypotension during epidural Anaesthesia. Acta Anaesthesiol Scand 1984;28:595-599.

9. Cook R, Malmqvist LA, Bengtsson M, et al. Vagal and sympathetic activity during spinal analgesia. Acta Anaesthesiol Scand 1990;34:271-275.

10. Cullingford DWJ. The blood sugar response to anaesthesia and surgery in Southern Indians. $\mathrm{Br} \mathrm{J}$ Anaesth 1966;38:463-470.

11. Aitkenhead AR, Rowbotham DJ, Smith G. Textbook of Anaesthesia. Churchill Livingstone, imprint of Harcourt publishers. 2001;301-04.

12. Hofer RE, Lanier WL. Effect of hydroxyethyl starch solutions on blood glucose concentrations in diabetic and non-diabetic rats. Crit Care Med 1992;20:211-5.

13. Murty SS, Kamath SK, Chaudhari LS. Effects of hydroxyethyl-starches on blood sugar levels: A randomised double blind study. Indian J Anaesth 2004;48:196-200.

14. Westphal M, James MF, Kozek-Langenecker SA, Stocker R, Guidet B, Van Aken H. Hydroxyethyl starches. Different products-different effects. Anesthesiology 2009;111:187-202.

15. Jungheinrich C. The starch family: Are they all equal? Pharmacokinetics and pharmacodynamics of hydroxyethyl starches. Transfus Altem Transfus Ivied 2007;9:152-63.

16. Desborough JP. The stress response to trauma and surgery. Br J Anaesth 2000;85:109-17.

17. Huiku M, Uutela K, van Gils M, Korhonen I, Kymäläinen $\mathrm{M}$, Meriläinen $\mathrm{P}$, et al. Assessment of surgical stress during general anaesthesia. $\mathrm{Br} \mathrm{J}$ Anaesth 1, 2007;98:447-55. 